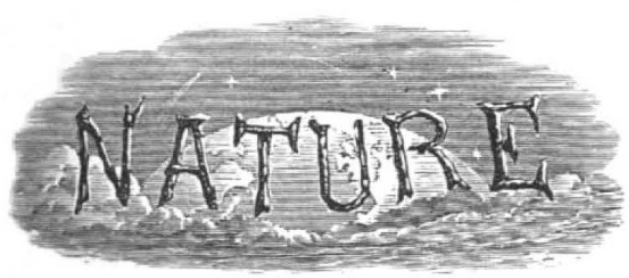

SATURDAY, AUGUST 22, I925.

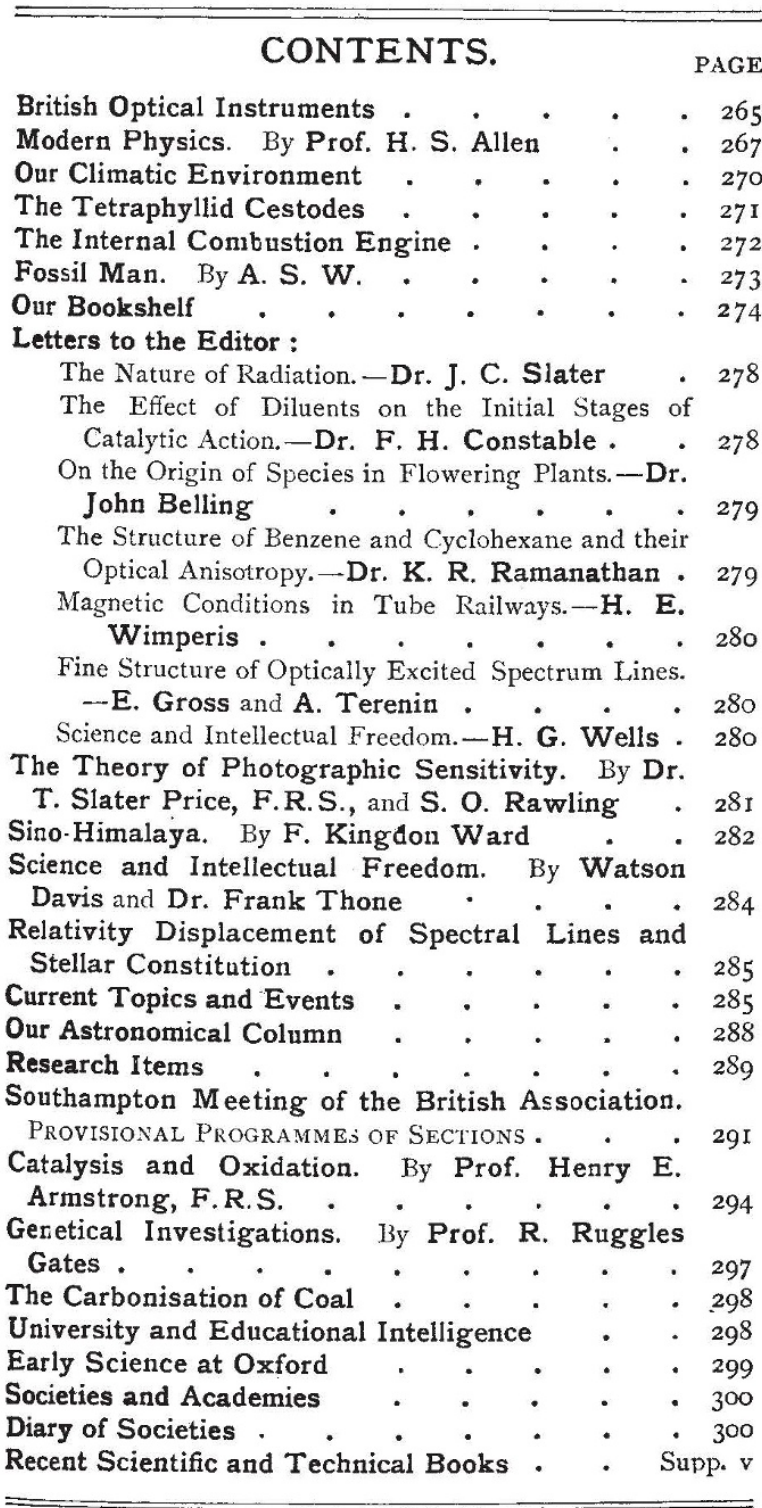

Editorial and Publishing Offices:

MACMILLAN \& CO., LTD.,

ST. MARTIN'S STREET, LONDON, W.C.2.

Editorial communications should be addressed to the Editor. Advertisements and business letters to the Publishers.

Telephone Number: GERRARD 8830.

Telegraphic Address: PHUSIS, WESTRAND, LONDON.

\section{British Optical Instruments.}

DROGRESS in nearly every branch of scientific investigation is dependent on the provision of suitable measuring apparatus. As the science develops, an ever-increasing degree of accuracy of measurement is required, which in its turn involves a correspondingly higher degree of refinement in the measuring apparatus. Many of the measuring instruments employed are essentially of an optical nature, and thus the optical instrument maker has been truly described as the toolmaker for all branches of scientific investigation including his own. It is the function and the duty of such a tool-maker to keep himself familiar with the latest advances in science, so as to be able to understand or even to anticipate the requirements of the investigator, and to meet these requirements by the provision of suitable practicable devices. That the British optical instrument maker has successfully fulfilled this function was clearly indicated by Mr. F. Twyman, who, in his recent presidential address to the British Optical Instrument Manufacturers' Association, discussed the capacity of the industry for invention, development, and production. His survey contained a record of notable achievements in regard to instrument design and construction of which any body of workers might justly be proud.

The economic stringency and the increased competition experienced during the past few years have stimulated the industry to increased efforts towards perfecting the quality and widening the range of its products, and towards improving and increasing its equipment for producing. Technically, the industry is in a healthy condition. Its research organisation, the British Scientific Instrument Research Association, has already proved of inestimable value. In addition, many of the individual firms in the industry actively prosecute research in their own laboratories; and these investigations are not simply directed towards putting forward new processes or improvements, but are often of a fundamental nature. This activity in research is reflected in the numbers of papers which have been published in recent years in the Transactions of the Optical Society and elsewhere, giving results of many important investigations carried out. by the scientific staffs of optical firms. Educational facilities in all branches of technical optics are provided in London at the Optical Engineering and Applied Optics Department of the Imperial College of Science and at the Northampton Polytechnic Institute. Thus, the scientific, technical, and educational equipment of the industry is such as to lead one to anticipate a continuance of the notable attainments which have characterised it in the past.

No. 29I2, vOL. I I6] 
The story of these achievements of the British optical instrument industry has never been sufficiently proclaimed, and the industry's commercial activities have probably not equalled, in extent or intensity, its technical and scientific abilities. For many years, German optical instruments have held a high reputation. This reputation has been well deserved. It has been built primarily on quality; but quality has been backed up by publicity, by advertisement, and by efficient commercial methods which, above all, rendered the selection and purchase of a suitable instrument a relatively simple matter. To-day, the products of the optical glass industry and the optical instrument industry of Great Britain are well able to compete with those of any other country, and in many directions they have established a distinct supremacy.

If an examination were made of similar types of optical glasses obtained through the ordinary commercial channels from British and from foreign makers, we believe that the results would show that the former are in several respects superior to the latter. It is unfortunate that no detailed authoritative statement on this subject has yet been published. In regard to microscopes, the best British stands have been, for long, unsurpassed, and many notable advances have recently been made in the optical parts. British microscope manufacturers have now provided a series of apochromatic objectives which are superior to any made in any other country. They have also introduced improvements in illuminating systems, a darkground illuminator having been developed which permits the use of higher powers than was hitherto possible.

The superiority of British camera lenses has been frequently demonstrated. Photographic lenses for aerial survey, the specification for which is particularly severe, have been supplied to foreign countries by British makers in open competition with the rest of the world. The photographic lenses of aperture $\mathrm{F} / 2$ recently produced in Britain were the first lenses of such great rapidity, and are still distinctly the best of their class. The only foreign-made lens of an equivalent speed covers about two-thirds the width of field of the British lens. The telephoto lens, which originated in Britain, has been improved so as to suit the varied and extended uses to which it is now being applied, and the British lens of this type still holds a foremost place.

For astronomical instruments and for instruments used in astrophysics, no country stands higher in reputation than Great Britain. Since the War, British makers of surveying instruments have re-designed most of their instruments, and have effected improvements, not only in design, but also in construction and in sub- sequent performance. The quality of the instruments is indicated by the fact that satisfactory sales are being effected abroad in the face of particularly severe competition from other countries. The best British binoculars now being manufactured are a little better than the best of the same class made abroad, and in addition, binoculars have now been made here which have a larger field of view than any others at present on the market.

For many years, the premier manufacturers of rangefinders in the world have been British, and before the War, foreign governments were probably their best customers. During these latter years, these manufacturers have continued to develop and improve their products, which for quality and efficiency are still unsurpassed.

British optical instruments for physical research form another branch with a deservedly high reputation. Complete equipments for dealing in a broad way with various special fields of research, such as the electron theory of matter, have been supplied by British manufacturers to laboratories in practically every country in Europe, as well as to the United States of America, Japan, and various parts of the British Empire. It is probable that most of the research of the world in certain fields of prime importance in modern physics is being done with British-made instruments.

On its own initiative, the optical instrument industry during the past ten years has developed apparatus for the testing of optical elements and optical instruments. This apparatus, in one or other of its various forms, will measure interferometrically the errors and imperfections of any kind of optical instrument, such as, for example, an astronomical telescope, a microscope, camera lens, or binocular. Photographs of the imperfections can easily be obtained, and these constitute unquestionable records. The apparatus in now in use in Britain and also in certain factories and State testing institutions abroad. It is thus possible for manufacturers to have applied to their lenses a test which is free from all elements of judgment, and to have the results stated in numerical measurement.

Enough has been said to show that, from a technical point of view, the British optical instrument industry is active and vigorous. The existence of such an industry is vitally essential to progress in science and to the healthy development of the nation. Close co-operation between the scientific investigator and the optical instrument maker will facilitate a continuance of that progress and development. Reference may be made in this connexion to recent investigations on filter-passing micro-organisms. Adequate instrumental facilities for investigations on such organisms were not in existence a year or two ago. The investigators knew the limita-

NO. 29I2, VOL. I I6] 
tions of their apparatus and knew what their requirements were. They placed their knowledge and requirements before the instrument maker, and in a comparatively few months were supplied with the instruments which enabled them to go further and deeper into their work and to obtain those important results which have recently been published. The work involved the construction of a microscope stand with an accuracy of focussing and a rigidity not provided by any existing stand, and also of an entirely novel combined illuminator, in which a high aperture dark-ground illuminator is mounted concentrically with, and encircling, a quartz condenser. The former secures visibility and is used to locate the micro-organisms, while the latter is used with ultra-violet light to obtain the image on the photographic plate.

Many examples could be given of the services rendered by the optician in the provision of special apparatus, often very complex and ingeniously designed, for the control of industrial processes. The efficiency of the British optical instrument industry has been, to a large extent, responsible for the rapidly growing use of optical projection apparatus in connexion with industry.

It is obviously in the interests of the scientific investigator, whether his work lies in the academic or in the industrial field, that there should be in the country in which he works, a progressive and efficiently equipped optical instrument-making industry. Such an industry does not exist on the production of specialised instruments alone. The more frequently recurring demands for instruments of the less elaborate types have also to be met. The production of these provides training and experience for the members of the industry. Production is regulated by demand. The greater the demand for British-made optical instruments, even of the simpler type, the wider will be the field from which may be recruited the craftsmen, the artists, and the scientific designers, all of whom are required in the production of many of the masterpieces which emanate from the optician's workshop or laboratory.

The contributions made by the optical instrument industry of Great Britain both to science and to industry entitle it to support and encouragement by every section of the nation. During times of peaceful progress, as much as during war and strife, a prosperous and active optical instrument industry is an important national asset, the influence of which may extend far beyond mere national boundaries. It should only be necessary for the users in Great Britain of optical instruments to be made fully aware of the industry's attainments and capabilities, and also of the range and quality of its productions, to ensure that such support and encouragement will not be lacking.

\section{Modern Pliysics.}

(r) Die Methoden der theoretischen Physik. Von Felix Auerbach. Pp. $\mathrm{x}+436$. (Leipzig: Akademische Verlagsgesellschaft m.b.H., I925.) I3 gold marks.

(2) Introduction to Theoretical Physics. By Prof. Arthur Haas. Translated from the third and fourth editions by T. Verschoyle. Vol. I. Pp. xiv $+33 \mathbf{I}$. (London, Bombay and Sydney: Constable and Co., Ltd., I924.) 2 Is. net.

(3) Physics: a Text-book for Colleges. By Prof. Oscar M. Stewart. Pp. viii +723 . (Boston and London : Ginn and Co., I924.) I7s. 6d. net.

(4) Lehrbuch der Physik in elementarer Darstellung. Von Arnold Berliner. Dritte Auflage. Pp. $\mathrm{x}+645$. (Berlin : Julius Springer, I924.) I8.60 gold marks.

$\mathrm{T}$ the older British universities the term natural philosophy is still used to denote one of the main branches of study. In I 747 we find Mr. David Young appointed to be "professor of natural and experimental philosophy" in the United College of St. Salvator and St. Leonard in the University of St. Andrews. In the Scottish universities, applied mathematics fell within the province of the department of natural philosophy. There lies before us an M.A. diploma of the University of Glasgow, dated 1863 , signed, amongst others, by Gul. Thomson, Phil. Nat. Prof. There is something to be said for retaining the more sonorous designation natural philosophy, at least for official purposes, in preference to the more compact term physics. It is the science which treats of the general properties of natural bodies. "The philosophy of science," says Prof. Whitehead, " is the endeavour to formulate the most general character of things observed." The changes which have taken place in our outlook upon natural phenomena during the first quarter of the present century have been profound, but yet they must be described as evolutionary rather than as revolutionary in character. Not only have there been brilliant experimental discoveries, resulting in entirely new methods of investigation, but also during the same period new theoretical conceptions have been introduced by Planck, Einstein, and Bohr, which have led to much questioning as to the fundamentals of our philosophy.

These developments, which have been discussed in a very large number of special treatises, have tended to render many of the older text-books, if not obsolete, at least imperfect and incomplete. The time has now arrived when it appears necessary to make provision for the new knowledge by revised and extended treatment. The task is no easy one, partly because of the rapid accumulation of new material and partly on account of our imperfect grasp of the new theories 